\title{
Incidence, risk factors and clinical course of pyogenic spondylodiscitis patients with pulmonary embolism
}

\author{
Daniel Dubinski ${ }^{1}$ - Sae-Yeon Won ${ }^{1} \cdot$ Fee Keil ${ }^{2} \cdot$ Bedjan Behmanesh ${ }^{1} \cdot$ Max Dosch ${ }^{1}$ Peter Baumgarten ${ }^{1}$. \\ Joshua D. Bernstock ${ }^{3} \cdot$ Volker Seifert $^{1} \cdot$ Thomas M. Freiman $^{1} \cdot$ Florian Gessler $^{1}$
}

Received: 8 January 2021 / Accepted: 19 August 2021 / Published online: 2 September 2021

(c) The Author(s) 2021

\begin{abstract}
Purpose In patients with pyogenic spondylodiscitis, surgery is considered the treatment of choice to conduct proper debridement, stabilise the spine and avoid extended bed rest, which in turn is a risk factor for complications such as deep vein thrombosis and pulmonary embolism.

Methods We conducted a retrospective clinical study with analysis of a group of 99 patients who had undergone treatment for pyogenic discitis at our institution between June 2012 and August 2017. Included parameters were age, sex, disease pattern, the presence of deep vein thrombosis, resuscitation, in-hospital mortality, present anticoagulation, preexisting comorbidities, tobacco abuse, body mass index, microbiological germ detection and laboratory results.

Results Among the analysed cohort, $12 \%$ of the treated patients for pyogenic spondylodiscitis suffered from a radiologically confirmed pulmonary embolism. Coronary heart disease $(p<0.01)$, female sex $(p<0.01)$, anticoagulation at admission $(p<0.01)$ and non-O blood type $(p<0.001)$ were associated with development of pulmonary embolism. Pulmonary embolism was significantly associated with resuscitation $(p<0.005)$ and deep vein thrombosis $(p<0.001)$. Neurosurgery was not associated with increased risk for pulmonary embolism compared to conservative-treated patients $(p>0.05)$.

Conclusion Surgery for pyogenic spondylodiscitis was not associated with an elevated risk of pulmonary embolism in our analysis. However, we describe several risk factors for pulmonary embolism in this vulnerable cohort. Prospective studies are necessary to improve prevention and postoperative management in patients with pyogenic spondylodiscitis.
\end{abstract}

Keywords Pulmonary embolism $\cdot$ Pyogenic spondylodiscitis $\cdot$ Risk factor $\cdot$ Coronary heart disease

\section{Introduction}

Pyogenic spondylodiscitis is a rare disease with high morbidity and consecutive long-term sequelae [1]. The bacterial infection is usually of hematogenic origin and transmitted from the oral cavity, the respiratory tract or the skin [2,3]. The primary site of infection is the avascular disc, the infection may then spread continually into the vertebral body and up into the subligamentous paravertebral area, epidural space

Daniel Dubinski

danieldubinski@gmail.com

1 Department of Neurosurgery, University Hospital, Goethe University, Schleusenweg 2-16, 60598 Frankfurt, Germany

2 Institute of Neuroradiology, University Hospital, Goethe University, Frankfurt, Germany

3 Department of Neurosurgery, Brigham and Women's Hospital, Harvard Medical School, Boston, MA, USA and contiguous vertebral bodies. In consequence, back pain and limitation of spine movement are the predominant signs in patients with spondylodiscitis $[4,5]$. Treatment concepts of pyogenic spondylodiscitis include either a conservative or a surgical management and should be evaluated individually. The currently available therapeutic guidelines are not standardised and based on individual preferences resulting in a high variability of outcome with conflicting results [6-8].

The conservative treatment consists of germ-compatible long-term antibiotic treatment and immobilisation of the spine [5, 9]. In patients with progressive neurologic deficits, large abscesses, progressive deformities or involvement of at least two adjacent vertebral bodies, surgical management should be favoured [10]. Surgical strategies are versatile and include extensive debridement of the disc and vertebral bodies, stabilisation and titanium mesh cages [10, 11]. Hence, patients treated for pyogenic spondylodiscitis harbour a numerous amount of well-established risk factors 
for pulmonary embolism such as immobilisation and prolonged bed rest, infection and bacteremia, operation and neurological deficits such as paralysis or paraplegia $[12,13]$. The currently lacking literature on patients with pyogenic spondylodiscitis and pulmonary embolism in the scientific literature prompted this study. Per our hypothesis, patients with pulmonary embolism may accommodate risk factors that are currently unknown to the literature. The identification of such risk factors may contribute to future concepts for thromboprophylaxis in this demanding cohort.

\section{Methods}

\section{Study design}

The present analysis is a retrospective, single centre observational study of patients with pyogenic spondylodiscitis. The hypothesis of the study was that several, to date largely unknown, risk factors contribute to the development of pulmonary embolism in patients with pyogenic spondylodiscitis. The identification of these could lead to a better risk stratification and adjusted anticoagulation regimes in this vulnerable cohort and potentially improve outcome.

\section{Patients and data collection}

For this retrospective analysis, an ethical approval was obtained by the local ethics committee (identification number: 20-683). As a non-interventional single-centre study no patient consent was necessary. Patients over 18-years old who were surgically or conservatively treated for pyogenic spondylodiscitis from 2012 to 2017 were identified retrospectively. Diagnosis of pyogenic spondylodiscitis was made upon clinical evaluation and spinal MRI with contrast agent. Indication for surgery was based upon individual case by case discussion including patients will, neurologic deficit, large abscesses, or involvement of at least two adjacent vertebral bodies. Surgery and postoperative management was performed as described before [14, 15]. Indication for thoracic CT scan was acute onset of one, or the combination of the following symptoms: collapse upon mobilisation, shock, hypotonia, tachycardia, dyspnoea, chest pain or dip in oxygen saturation [16]. Patients with a pre-existing haematological disorder (e.g. factor V Leiden, prothrombin mutation, protein $\mathrm{C} / \mathrm{S}$ deficiency, leukaemia, lymphoma, systemic amyloidosis) were excluded. Further exclusion criteria were treatment of patient for less than $48 \mathrm{~h}$. For venous thromboembolism (VTE) prophylaxis, all patients received s.c. low molecular-weight heparin (LMWH) within $48 \mathrm{~h}$ of admission. In patients with elective surgical procedures, phenprocoumon therapy was paused at least 2 weeks prior surgery and switched to therapeutic LMWH which was paused on the day of surgery. The primary outcome was in hospital mortality. All patients received $40 \mathrm{mg}$ of LMWH $\left(\right.$ Clexane $^{\circledR}$ ) subcutaneously starting on the first postoperative day. On the day of operation, $20 \mathrm{mg}$ of LMWH $\left(\right.$ Clexane $^{\circledR}$ ) were administered s.c. $10 \mathrm{~h}$ post-surgery. This anticoagulation concept was recommended by our department of hemostaseology and applied in our department for over 20 years. Mobilisation was anticipated as soon as possible and realised with the assistance of a physiotherapist. All patients were urged to wear compression stockings. Patients were seen in a follow-up examination 3-months post-surgery in our outpatient department.

\section{Computed tomography imaging}

Thoracic CT scans were performed in the department of neuroradiology at a multidetector Philips CT Scanner. Ultravist ${ }^{\circledR} 300$ was administered intravenously $(80 \mathrm{ml} / \mathrm{kg}$, $4.0 \mathrm{ml} / \mathrm{s}$ ) and imaging started after the contrasting of the pulmonary artery.

\section{Spinal MRI}

All patients received spinal MRI in the department of neuroradiology, Goethe University Hospital Frankfurt at a 3 Tesla Siemens Verio scanner. Gd-DO3A-butrol (Gadovist ${ }^{\circledR}$, Bayer Vital $\mathrm{GmbH})$ was administered intravenously $(0.1 \mathrm{ml} /$ $\mathrm{kg}$; max. $10 \mathrm{ml})$. T1w sagittal post contrast imaging started directly, axial $\mathrm{T} 1 \mathrm{w}$ post contrast imaging was preformed between 3 and 7 min after administration of the contrast agent.

\section{Statistics}

Data analysis was performed with IBM SPSS Statistics Version 23.0 (SPSS Inc., IBM Corp., Armonk, NY, USA). For patient characteristics, descriptive statistics were used. Fisher's exact test was used for the comparison of categorical variables between the cohorts. For continuous parameters, the Wilcoxon-Mann-Whitney test was used. To assess the impact of the variables, odds ratio (OR) with $95 \%$ confidence intervals (CI) was calculated. Results with $p \leq 0.05$ were considered statistically relevant.

\section{Results}

\section{Cohort characteristics}

A total of 110 patients with treatment of pyogenic spondylodiscitis were included. The observational time frame was 2012-2017. In total, two patients were excluded from the study due to a pre-existing hemostaseological burden and 
nine due to treatment less than $48 \mathrm{~h}$. Hence, a total of 99 patients with pyogenic spondylodiscitis were included in the analysis. A flow diagram is displayed in Fig. 1.

Overall, 59 patients $(60 \%)$ were male and median age was 75.5 (SD: 10.1) in the analysed cohort. The site of infection was distributed as following: cervical spine $12(12 \%)$ patients, thoracic spine 33 (33\%) patients and 54 (55\%) patients with spondylodiscitis of the lumbar spine. Neurosurgical intervention was performed in 72 cases (72\%). In detail, decompression was done in 18 patients $(25 \%)$, dorsal or ventral approach in 28 (39\%) and combined dorsoventral approach in $23(32 \%)$.

A pathogen detection could be obtained in 45 patients (45\%). In total, 51 patients had non-O blood type (52\%). In total 12 patients (12\%) suffered from postoperative PE. Resuscitation (defibrillation, chest compression, intubation and pharmacological intervention) was necessary in four patients (4\%). Deep vein thrombosis was confirmed in two patients (2\%) and four patients died during the hospital stay (4\%). Four patients had a known history of tobacco abuse (4\%) and obesity was observed in 21 patients $(21 \%)$. Anticoagulation at admission (phenprocoumon, LMWH, platelet aggregation inhibitors or direct oral anticoagulants) was present in 24 patients (24\%), coronary heart disease was present in 16 patients $(16 \%)$ and hypertension in $32(32 \%)$ of the analysed cohort. Diabetes mellitus was observed in $26(26 \%)$ patients and four patients (5\%) were on antidepressants at admission. See Table 1.

\section{Risk factors for pulmonary embolism in pyogenic spondylodiscitis}

Female sex was significantly associated with PE $(p<0.01)$. The median age in the PE positive group was 82 (SD: 10) and 76 (SD: 14.6) in patients without PE. Patient age was not associated with PE development $(p=0.17)$. We further investigated the possible impact of the infection site on PE development. In total, two patients (17\%) with PE had pyogenic spondylodiscitis of the cervical spine and 9 $(11 \%)$ of the patients without PE cohort $(p=0.35)$. The thoracic spine was affected in three patients $(28 \%)$ in the PE cohort and 24 patients (27\%) in in patients without PE, and was therefore, not significantly correlated $(p=0.46)$. Lumbar spine was primary infected in seven patients in the
Fig. 1 Flow diagram displaying an overview of the patients included for analysis
A total of 110 patients with pyogenic spondylodiscitis were treated at the department of neurosurgery between 2012 to 2017

11 patients excluded:

- 9 treatment less than 48 hours

-2 hemostaseological comorbidity

99 patients were treated for pyogenic spondylodiscitis

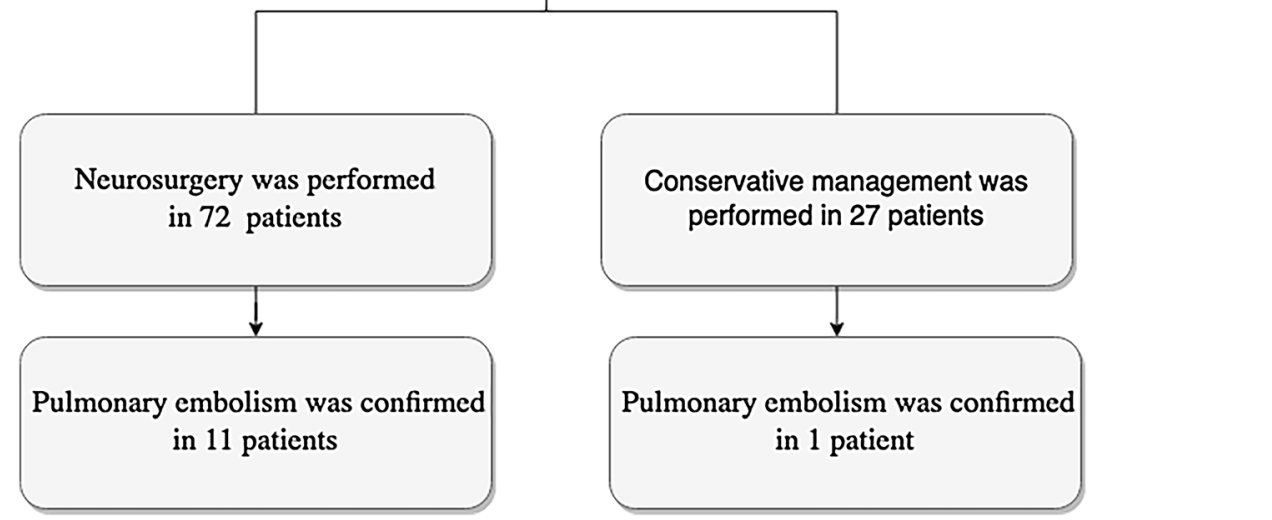


Table 1 Patient characteristics $(n=99)$

\begin{tabular}{|c|c|}
\hline & $n(\%)$ \\
\hline \multicolumn{2}{|l|}{ Sex } \\
\hline Male & $59(60)$ \\
\hline Female & $40(40)$ \\
\hline Age (SD) & $75.5(10.1)$ \\
\hline \multicolumn{2}{|l|}{ Location } \\
\hline Cervical spine & $12(12)$ \\
\hline Thoracic spine & $33(33)$ \\
\hline Lumbar spine & $54(55)$ \\
\hline \multicolumn{2}{|l|}{ Neurosurgery } \\
\hline Yes & $72(72)$ \\
\hline No & $27(28)$ \\
\hline \multicolumn{2}{|l|}{ Neurosurgical approach $(n=72)$} \\
\hline Decompression & $18(25)$ \\
\hline Dorsal or ventral approach & $28(39)$ \\
\hline Dorsoventral approach & $23(32)$ \\
\hline \multicolumn{2}{|l|}{ Laboratory results } \\
\hline Proof of germination & $45(45)$ \\
\hline Non-O blood type & $51(52)$ \\
\hline \multicolumn{2}{|l|}{ Pulmonary embolism } \\
\hline Yes & $12(12)$ \\
\hline No & $87(87)$ \\
\hline \multicolumn{2}{|l|}{ Morbidity and mortality } \\
\hline Resuscitation yes & $4(4)$ \\
\hline Resuscitation no & $95(96)$ \\
\hline Deep vein thrombosis (DVT) yes & $2(2)$ \\
\hline Deep vein thrombosis (DVT) no & $97(98)$ \\
\hline \multicolumn{2}{|l|}{ Outcome } \\
\hline Death & $4(4)$ \\
\hline Survival & $95(96)$ \\
\hline \multicolumn{2}{|l|}{ Risk factors } \\
\hline Tobacco abuse yes & $4(4)$ \\
\hline Tobacco abuse no & $95(96)$ \\
\hline Obesity yes & $21(21)$ \\
\hline Obesity no & $78(78)$ \\
\hline \multicolumn{2}{|l|}{ Pre-existing comorbidities } \\
\hline Coronary heart disease yes & $16(16)$ \\
\hline Coronary heart disease no & $83(84)$ \\
\hline Hypertension yes & $32(32)$ \\
\hline Hypertension no & $67(68)$ \\
\hline Diabetes mellitus yes & $26(26)$ \\
\hline Diabetes mellitus no & $73(74)$ \\
\hline \multicolumn{2}{|l|}{ Medication at admission } \\
\hline Anticoagulation yes & $24(24)$ \\
\hline Anticoagulation no & $75(76)$ \\
\hline Antidepressants yes & $5(5)$ \\
\hline Antidepressants no & $94(95)$ \\
\hline
\end{tabular}

$S D$ standard deviation
PE cohort (58\%) and 54 patients (62\%) of patients without $\mathrm{PE}$ and therefore not significantly associated $(p=0.59)$. Neurosurgical intervention was performed in 72 cases in which 11 patients developed PE vs. a total of 26 patients with conservative treatment in which one patient developed PE. Neurosurgical intervention was therefore not statistically significant in PE development $(p=0.17)$.

In detail, in patients who underwent spinal decompression seven patients (64\%) developed PE vs 23 (38\%) without PE detection. In patients with dorsal or ventral approach 2 (18\%) patients developed PE vs 17 (28\%) without PE development. Furthermore, in patients with combined dorsoventral approach, two patients (18\%) developed PE vs. 21 (34\%) without PE. The operative approach, was therefore, not significantly associated with PE $(p=0.18)$; $(p=0.71)$ and $(p=0.32)$, respectively.

The proof of germination (Blood cultures and/or operative smear) was achieved in $7(63 \%)$ patients in the PE cohort and $28(46 \%)$ in the control group $(p=0.18)$. All patients $(n=11)$ had non-O blood type in the PE cohort and $26(42 \%)$ in the control group. Patient blood type was significantly associated with PE risk $(p=0.001)$ (Table 2).

Furthermore, anticoagulation at admission was present in six patients (50\%) in the PE cohort vs. $14(16 \%)$ in the PE negative cohort. The presence of anticoagulation at admission was therefore statistically significant associated with PE development $(p=0.01)$.

\section{Acquired risk factors}

Tobacco abuse was observed in one patient in the PE group (9\%) and five patients in the PE negative cohort $(6 \%)$, and was therefore, not associated with $\mathrm{PE}(p=1)$. Obesity was present in two patients in the PE cohort (17\%) and $15(17 \%)$ in patients without PE detection, and was therefore, not significantly associated $(p=1)$. See Table 2 .

\section{Pre-existing comorbidities}

Coronary heart disease was present in five patients (42\%) with PE and nine patients (10\%) without PE development. The presence of coronary heart disease was significantly associated with PE onset $(p=0.01)$. Further, hypertension was present in six patients (55\%) in the PE group and 21 patients $(24 \%)$ in the PE negative cohort $(p=0.08)$. Diabetes mellitus was present in two patients (17\%) in the PE cohort and in 19 patients (21\%) without PE development. The presence of diabetes mellitus, was therefore, not associated with PE onset $(p=1)$. See Table 2. 
Table 2 Univariate analysis of patients with pyogenic spondylodiscitis with radiographically confirmed or unconfirmed pulmonary embolism as the dependent variable

\begin{tabular}{|c|c|c|c|c|c|}
\hline \multirow[t]{2}{*}{ Patient characteristics } & \multicolumn{2}{|c|}{ Pulmonary embolism } & \multicolumn{3}{|c|}{ Univariate analysis } \\
\hline & Yes $(n=12)$ & No $(n=87)$ & $\overline{\mathrm{OR}}$ & $95 \% \mathrm{CI}$ & $p$ value \\
\hline \multicolumn{6}{|l|}{ Sex } \\
\hline Female, $(\%)$ & $9(75)$ & $32(37)$ & 5.89 & $1.40-24.71$ & $\mathbf{0 . 0 1}$ \\
\hline Age, (SD) & $82(10)$ & $76(14.6)$ & $\mathrm{n} / \mathrm{a}$ & $2.84-14.82$ & 0.17 \\
\hline \multicolumn{6}{|l|}{ Location } \\
\hline Cervical spine, $(\%)$ & $2(17)$ & $9(11)$ & 2.03 & $0.35-11.70$ & 0.35 \\
\hline Thoracic spine, $(\%)$ & $3(25)$ & $24(27)$ & 0.71 & $0.17-2.97$ & 0.46 \\
\hline Lumbar spine, $(\%)$ & $7(58)$ & $54(62)$ & 0.95 & $0.26-3.56$ & 0.59 \\
\hline No neurosurgical intervention, (\%) & 1 & 26 & 0.21 & $0.02-1.73$ & 0.17 \\
\hline Neurosurgery, (\%) & 11 & 61 & & & \\
\hline \multicolumn{6}{|l|}{ Neurosurgical approach $(n=72)$} \\
\hline Decompression, $(\%)$ & $7(64)$ & $23(38)$ & 2.89 & $0.76-10.96$ & 0.18 \\
\hline Dorsal or ventral approach, $(\%)$ & $2(18)$ & $17(28)$ & 0.57 & $0.11-2.93$ & 0.71 \\
\hline Dorsoventral approach, (\%) & $2(18)$ & $21(34)$ & 0.42 & $0.08-2.14$ & 0.32 \\
\hline \multicolumn{6}{|l|}{ Laboratory results } \\
\hline Proof of germination, $(\%)$ & $8(66)$ & $41(47)$ & 2.24 & $0.62-8.00$ & 0.23 \\
\hline Non-O blood type, (\%) & $12(100)$ & $39(44)$ & $\mathrm{n} / \mathrm{a}$ & $0.31-0.57$ & 0.001 \\
\hline \multicolumn{6}{|l|}{ Morbidity and mortality } \\
\hline Resuscitation, (\%) & $3(25)$ & $1(1)$ & 28.6 & $2.69-305.15$ & 0.005 \\
\hline Deep vein thrombosis, $(\%)$ & $3(25)$ & $0(0)$ & $\mathrm{n} / \mathrm{a}$ & $\mathrm{n} / \mathrm{a}$ & 0.001 \\
\hline \multicolumn{6}{|l|}{ Outcome } \\
\hline Death, $(\%)$ & $1(8)$ & $0(0)$ & $\mathrm{n} / \mathrm{a}$ & $\mathrm{n} / \mathrm{a}$ & 0.12 \\
\hline \multicolumn{6}{|l|}{ Risk factors } \\
\hline Tobacco abuse, $(\%)$ & $1(9)$ & $5(6)$ & 1.4 & $0.15-13.96$ & 1 \\
\hline Obesity, (\%) & $2(17)$ & $15(17)$ & 0.96 & $0.19-4.83$ & 1 \\
\hline \multicolumn{6}{|l|}{ Pre-existing conditions } \\
\hline Coronary heart disease, $(\%)$ & ä & $9(10)$ & 6.19 & $1.62-23.62$ & 0.01 \\
\hline Hypertension, (\%) & $6(50)$ & $21(24)$ & 3.14 & $0.91-10.78$ & 0.08 \\
\hline Diabetes mellitus, $(\%)$ & $2(17)$ & $19(21)$ & 0.71 & $0.14-3.54$ & 1 \\
\hline \multicolumn{6}{|l|}{ Medication at admission } \\
\hline Anticoagulation, (\%) & $6(50)$ & $14(16)$ & 5.21 & $1.46-18.52$ & 0.01 \\
\hline Antidepressants, (\%) & $1(8)$ & $5(6)$ & 1.49 & $0.15-13.96$ & 1 \\
\hline
\end{tabular}

\section{Morbidity and mortality}

Resuscitation was performed on three patients $(25 \%)$ in the PE cohort and in $1(1 \%)$ patient without PE development, and was therefore, significantly correlated $(p=0.005)$. Deep vein thrombosis was confirmed in three patients (25\%) in the PE group and no patient without PE development and was significantly associated with the diagnosis of PE $(p=0.001)$. One patient died in the PE cohort (8\%); whereas, none of the patients in the PE negative cohort. The in-hospital mortality, was therefore, not significantly associated with PE $p=0.12$. See Table 2 .

\section{Discussion}

To the best of our knowledge the present study is the first to describe the remarkably high incidence of $\mathrm{PE}$ in patients with pyogenic spondylodiscitis compared to published numbers of other surgical disciplines [17-19]. Furthermore, we identified female sex, higher age, coronary heart disease, 
anticoagulation at admission and non-O blood type as significant risk factors for PE. PE was associated with DVT and resuscitation. Surprisingly, neither surgical intervention itself nor the chosen approach were associated with elevated PE risk compared to conservatively treated patients.

In our cohort, $12 \%$ of the included patients with pyogenic spondylodiscitis suffered from PE. This incidence appears to be significantly higher than described in the scientific literature. As for example studies on PE after orthopaedic surgeries, including a large series of spinal surgeries, vary from 2 to $6 \%[16,20,21]$. However, the published variety of PE manifestation among spinal surgery is extremely high as other studies report an incidence of up to $31 \%$ (i.e. patients with major spinal reconstruction) [17, 18]. Our finding therefore amends to the published knowledge and raises the question of preventive scopes of action and anticoagulation management in patients with surgical interventions for pyogenic spondylodiscitis and those with conservative management.

The finding of significantly overrepresented female patients in the PE cohort is intriguing as data on whether patient sex is a risk factor for pulmonary embolism is conflicting. An analysis of national mortality data found that death rates from PE were up to $30 \%$ higher among men than among women [21]. Although female sex was not found to be a significant risk factor in large unselected observational studies, female patients with PE had higher in-hospital mortality, a higher need for transfusion and occurrence of shock [22].

Further, all patients in our PE cohort had non-O blood type. The difference in hemostaseological properties of $\mathrm{ABO}$ antigens led to the identification of non-O blood type as a significant risk factor for postoperative thrombosis and embolism [23, 24]. Our finding is in line with this observation and demonstrates a significant association of patient blood type and for postoperative PE in patients with pyogenic spondylodiscitis.

Several publications claim that patients with high BMI are at elevated risk for PE [19]. In specific, excessive visceral adipose tissue causes hypoxia and increases free fatty acids (FFA) to the liver where coagulation factors are synthesised [25]. However, our study found no association between patients BMI and PE. A possible explanatory approach is the fact that in our analysis the investigated BMI was obtained at admission. Since pyogenic spondylodiscitis is a disease of mid- to long-term duration, patient BMI was subject to fluctuations after admission and thus not detected in our analysis.

In our cohort, the presence of anticoagulation at admission was associated with PE. This finding is challenging. All patients on anticoagulation were converted to LMWH prior to neurosurgery as described in the methods section. In most cases, the rational for anticoagulation was a positive history for DVT or PE. The underlying coagulation disorder that led to DVT or PE in the first place could therefore be accountable for PE in our cohort. Furthermore, a reactive hypercoagulability state or an increased hemostaseological response could also be made accountable for this association. The American College of Chest Physicians (ACCP) and the Eastern Association for the Surgery of Trauma (EAST) have recommended the use of low-dose unfractionated heparin (UFH) or low molecular weight heparin (LMWH) with or without mechanical prophylaxis for the prevention of VTE complications but they are unclear on timing its initiation $[26,27]$. However, we here described our individual approach of administering $20 \mathrm{mg} \mathrm{LMWH}$ $10 \mathrm{~h}$ postoperatively and report a satisfactory result in postoperative management since our surgically treated patients did not show an increased PE development compared to the conservatively treated.

We found coronary heart disease to be significantly associated with PE in our cohort. Although, we are not aware of other studies that explored the association between pyogenic spondylodiscitis and PE, the increased risk of PE after the diagnosis of coronary heart diseases is known in literature and explained by the fact that coronary heart diseases induce venous stasis and elevated systemic venous pressure [28, 29]. In our cohort, this phenomenon could be aggravated by the present bacteremia, with often infective endocarditis and consecutive further deterioration [30].

In our cohort, patients with PE had a significant association with DVT and resuscitation. The complex situation of a hazardous cardiovascular event with often inevitable longterm anticoagulation after a recent neurosurgical procedure is a known risk factor for poor outcome and coherent with the scientific literature [20,23].

Furthermore, we found surgical intervention for pyogenic spondylodiscitis to be a non-significant risk factor for PE when compared to a conservative treated cohort. This finding is surprising since major surgery is a well-established risk factor for PE development in the scientific literature [31-33]. The complexity and long duration of both conditions could be accountable for this finding. Hypothetically, surgery could be accountable for a periodic hypercoagulability state with increased thrombotic potential but the benefit of early mobilisation could counterbalance this finding when compared to prolonged bed rest in conservative managed patients.

The obvious limitation is that this investigation was a single centre study and of retrospective design. As this study is of observational character, confounding, selection bias, reverse causation and uncontrolled statistical error risk cannot be excluded. Further, the small sample size of our PE cohort is a possible confounder which should be addressed in future prospective multicentre studies. Despite the relative high incidence of PE in our surgical cohort, when compared 
to conservative treated patients the sequela is non-hazardous. Only one patient died in the PE cohort. In contrast, data from patients with spinal cord injury display a DVT incidence of almost $100 \%[34,35]$. The benefits of surgical treatment in patients with pyogenic spondylodiscitis (bacterial detection, reduced bed rest and early ambulation) outweighs the incidence of PE. Because of the small sample a size specific interaction between the variables measured by a multivariate analysis was not possible. Ultimately, a randomised clinical trial is necessary to verify our findings.

\section{Conclusion}

Evidence provided by our study may improve our understanding of the risk factors for PE associated with the treatment of patients with pyogenic spondylodiscitis and may potentially lead to improved prevention and postoperative management.

Author contribution DD collected the data and wrote the first draft. FG supervised the manuscript. All authors supplied additional information, edited the manuscript and contributed to critical review and revision of the manuscript.

Funding Open Access funding enabled and organized by Projekt DEAL. No funding was received for this research.

\section{Declarations}

Conflict of interest All authors certify that they have no affiliations with or involvement in any organisation or entity with any financial interest (such as honoraria; educational grants; participation in speakers' bureaus; membership, employment, consultancies, stock ownership, or other equity interest; and expert testimony or patent-licencing arrangements), or non-financial interest (such as personal or professional relationships, affiliations, knowledge or beliefs) in the subject matter or materials discussed in this manuscript.

Ethical approval All procedures performed in studies involving human participants were in accordance with the ethical standards of the institutional ethics committee of the University Hospital Frankfurt (Identification number: 20-683) and with the 1964 Helsinki declaration and its later amendments or comparable ethical standards. For this type of study formal consent is not required.

Informed consent This article does not contain any studies with human participants performed by any of the authors.

Open Access This article is licensed under a Creative Commons Attribution 4.0 International License, which permits use, sharing, adaptation, distribution and reproduction in any medium or format, as long as you give appropriate credit to the original author(s) and the source, provide a link to the Creative Commons licence, and indicate if changes were made. The images or other third party material in this article are included in the article's Creative Commons licence, unless indicated otherwise in a credit line to the material. If material is not included in the article's Creative Commons licence and your intended use is not permitted by statutory regulation or exceeds the permitted use, you will need to obtain permission directly from the copyright holder. To view a copy of this licence, visit http://creativecommons.org/licenses/by/4.0/.

\section{References}

1. Patel AR, Alton TB, Bransford RJ, Lee MJ, Bellabarba CB, Chapman JR. Spinal epidural abscesses: risk factors, medical versus surgical management, a retrospective review of 128 cases. Spine J. 2014;14:326-30.

2. Hadjipavlou AG, Mader JT, Necessary JT, Muffoletto AJ. Hematogenous pyogenic spinal infections and their surgical management. Spine (Phila Pa 1976). 2000;25:1668-79.

3. Stricsek G, Iorio J, Mosley Y, Prasad S, Heller J, Jallo J, et al. Etiology and surgical management of cervical spinal epidural abscess (SEA): a systematic review. Glob Spine J. 2018;8:59S-67S.

4. Mann S, Schütze M, Sola S, Piek J. Nonspecific pyogenic spondylodiscitis: clinical manifestations, surgical treatment, and outcome in 24 patients. Neurosurg Focus. 2004;17:1.

5. Luo CA, Tsai TT, Lu ML, Hsieh MK, Lai PL, Fu TS, et al. Factors related to post surgical neurologic improvement for cervical spine infection. Biomed J. 2018;41:306-13.

6. Bürger J, Palmowski Y, Pumberger M (2020) Comprehensive treatment algorithm of postoperative spinal implant infection. $\mathrm{J}$ spine Surg (Hong Kong). AME Publishing Company 6:793-9. Available from: http://www.ncbi.nlm.nih.gov/pubmed/33447685. Accessed 2021 Apr 26

7. Tsai TT, Yang SC, Niu CC, Lai PL, Lee MH, Chen LH, et al. Early surgery with antibiotics treatment had better clinical outcomes than antibiotics treatment alone in patients with pyogenic spondylodiscitis: a retrospective cohort study. BMC Musculoskelet Disord. 2017;18:1.

8. Rutges JPHJ, Kempen DH, van Dijk M, Oner FC (2016) Outcome of conservative and surgical treatment of pyogenic spondylodiscitis: a systematic literature review. Eur Spine J. Springer Verlag. p. 983-99. Available from: https://pubmed.ncbi.nlm.nih.gov/26585 975/. Accessed 2021 Apr 26

9. Taylor DG, Buchholz AL, Sure DR, Buell TJ, Nguyen JH, Chen $\mathrm{CJ}$, et al. Presentation and outcomes after medical and surgical treatment versus medical treatment alone of spontaneous infectious spondylodiscitis: a systematic literature review and metaanalysis. Glob Spine J. 2018;8:49S-58S.

10. Kuklo TR, Potter BK, Bell RS, Moquin RR, Rosner MK. Singlestage treatment of pyogenic spinal infection with titanium mesh cages. J Spinal Disord Tech. 2006;19:376-82.

11. Hee HT, Majd ME, Holt RT, Pienkowski D. Better treatment of vertebral osteomyelitis using posterior stabilization and titanium mesh cages. J Spinal Disord Tech. 2002;15:149-56.

12. White RH, Brunson A, Romano PS, Li Z, Wun T. Outcomes after vena cava filter use in noncancer patients with acute venous thromboembolism. Circulation. 2016;133:2018-29. https://doi. org/10.1161/Circulationaha.115.020338.

13. Kline JA, Courtney DM, Kabrhel C, Moore CL, Smithline HA, Plewa MC, Plewa MC, et al. (2008) Prospective multicenter evaluation of the pulmonary embolism rule-out criteria. J Thromb Haemost 6:772-80. Available from: http://www.ncbi.nlm.nih.gov/ pubmed/18318689. Accessed 2019 Mar 8

14. Behmanesh B, Gessler F, Schnoes K, Dubinski D, Won S-Y, Konczalla J, et al. (2019) Infective endocarditis in patients with pyogenic spondylodiscitis: implications for diagnosis and therapy. Neurosurg Focus 46:E2. Available from: http://www.ncbi.nlm.nih. gov/pubmed/30611162. Accessed 2019 Jun 29

15. Gessler F, Mutlak H, Tizi K, Senft C, Setzer M, Seifert V, et al. Postoperative patient-controlled epidural analgesia in patients 
with spondylodiscitis and posterior spinal fusion surgery. J Neurosurg Spine. 2016;24:965.

16. Cha SI, Lee SY, Kim CH, Park JY, Jung TH, Yi JH, et al. Venous thromboembolism in Korean patients undergoing major orthopedic surgery: a prospective observational study using computed tomographic (CT) pulmonary angiography and indirect CT venography. J Korean Med Sci. 2010;25:28-34.

17. Leon L, Rodriguez H, Tawk RG, Ondra SL, Labropoulos N, Morasch MD. The prophylactic use of inferior vena cava filters in patients undergoing high-risk spinal surgery. Ann Vasc Surg. 2005;19:442-7.

18. Glotzbecker MP, Bono CM, Wood KB, Harris MB. Thromboembolic disease in spinal surgery: a systematic review. Spine (Phila Pa 1976). 2009;34:291-303.

19. Kong L, Meng F, Liu Z, Shen Y (2017) Prevalence and risk factors for venous thromboembolism after elective spinal surgery: a meta-analysis. Int J Clin Exp Med. Available from: www.ijcem. com/

20. Lee W-S, Kim K-I, Lee H-J, Kyung H-S, Seo S-S (2013) The Incidence of Pulmonary Embolism and Deep Vein Thrombosis After Knee Arthroplasty in Asians Remains Low: A Meta-analysis. Clin Orthop Relat Res [Internet]. Springer New York LLC 471:1523-32. Available from: http://journals.lww.com/00003086201305000-00020. Accessed 2020 Jun 1

21. Dearborn JT, Hu S, Tribus CB, Bradford DS. Thromboembolic complications after major thoracolumbar spine surgery. Spine (Phila Pa 1976). 1999;24:1471-6.

22. Agarwal S, Clark D, Sud K, Jaber WA, Cho L, Menon V. Gender disparities in outcomes and resource utilization for acute pulmonary embolism hospitalizations in the United States. Am J Cardiol. 2015;116:1270-6.

23. Dubinski D, Keil F, Won SY, Behmanesh B, Jahnke K, Seifert V, et al. (2020) Pulmonary embolism in neurocritical care-introduction of a novel grading system for risk stratification: the Frankfurt AMBOS score. Neurosurg Rev 44:1165-1171

24. Dentali F, Sironi AP, Ageno W, Turato S, Bonfanti C, Frattini F et al. (2012) Non-O blood type is the commonest genetic risk factor for VTE: results from a meta-analysis of the literature. Semin Thromb Hemost 38:535-48. Available from: http://www.ncbi. nlm.nih.gov/pubmed/22740183. Accessed 2016 Mar 6

25. Stein PD, Beemath A, Olson RE. Obesity as a risk factor in venous thromboembolism. Am J Med Am J Med. 2005;118:978-80.

26. Zeeshan M, Khan M, O'Keeffe T, Pollack N, Hamidi M, Kulvatunyou N, et al. Optimal timing of initiation of thromboprophylaxis in spine trauma managed operatively: a nationwide propensitymatched analysis of trauma quality improvement program. J Trauma Acute Care Surg. 2018;85:387-92.
27. Hamidi M, Zeeshan M, Kulvatunyou N, Mitra HS, Hanna K, Tang A, et al. (2019) Operative spinal trauma: Thromboprophylaxis with low molecular weight heparin or a direct oral anticoagulant. J Thromb Haemost. Blackwell Publishing Ltd 17:925-33 Available from: https://pubmed.ncbi.nlm.nih.gov/30924300/. Accessed 2021 May 18

28. Olivieri O, Turcato G, Moruzzi S, Castagna A, Girelli D, Pizzolo F, et al. Not just arterial damage: increased incidence of venous thromboembolic events in cardiovascular patients with elevated plasma levels of apolipoprotein CIII. J Am Heart Assoc. 2019;8:e010973.

29. Sørensen HT, Horvath-Puho E, Lash TL, Christiansen CF, Pesavento R, Pedersen L, et al. (2011) Heart disease may be a risk factor for pulmonary embolism without peripheral deep venous thrombosis. Circulation. Lippincott Williams \& WilkinsHagerstown, MD 124:1435-41. Available from: http://www.ncbi.nlm. nih.gov/pubmed/21900083. Accessed 2020 Jun 5

30. Behmanesh B, Gessler F, Schnoes K, Dubinski D, Won SY, Konczalla $\mathbf{J}$, et al. Infective endocarditis in patients with pyogenic spondylodiscitis: implications for diagnosis and therapy. Neurosurg Focus. 2019;46:E2.

31. Piper K, Algattas H, DeAndrea-Lazarus IA, Kimmell KT, Li YM, Walter KA, et al. (2017) Risk factors associated with venous thromboembolism in patients undergoing spine surgery. J Neurosurg Spine [Internet]. American Association of Neurological Surgeons 26:90-6. Available from: https://pubmed.ncbi.nlm.nih. gov/27588916/. Accessed 2020 Dec 10

32. Geerts WH, Bergqvist D, Pineo GF, Heit JA, Samama CM, Lassen MR, et al. Prevention of venous thromboembolism: American College of chest physicians evidence-based clinical practice guidelines (8th edition). Chest. 2008;133:381S-453S.

33. Frederick A, Anderson J, Spencer FA. Risk factors for venous thromboembolism. Philadelphia: Circulation. Lippincott Williams \& Wilkins; 2003. https://doi.org/10.1161/01.CIR.0000078469. 07362.E6.

34. Myllynen P, Kammonen M, Rokkanen P, Böstman O, Lalla M, Laasonen E (1985 ) Deep Venous Thrombosis and Pulmonary Embolism in Patients with Acute Spinal Cord Injury. J Trauma Inj Infect Crit Care 25:541-3. Available from: http://journals.lww. com/00005373-198506000-00013. Accessed 2020 Jun 7

35. Raksin PB, Harrop JS, Anderson PA, Arnold PM, Chi JH, Dailey AT, et al. Congress of neurological surgeons systematic review and evidence-based guidelines on the evaluation and treatment of patients with thoracolumbar spine trauma: prophylaxis and treatment of thromboembolic events. Clin Neurosurg. 2019;84:E39-42. 